\title{
Phase 2 study of ceritinib in alectinib-pretreated patients with ALK-rearranged metastatic NSCLC in Japan: ASCEND-9
}

\section{Toyoaki Hida}

Takashi Seto

Hidehito Horinouchi

Makoto Maemondo

Masayuki Takeda

Katsuyuki Hotta

Fumihiko Hirai

Young Hak Kim

Shingo Matsumoto

Masayuki Ito

Koichi Ayukawa

Kota Tokushige

Masataka Yonemura

Testuya Mitsudomi

Makoto Nishio

\section{Video Abstract}

Keywords: ALK, anaplastic lymphoma kinase, NSCLC, non-small cell lung cancer, alectinib, ceritinib, survival, metastatic, mutation, ASCEND-9, Japan, rearrangement, rearranged, chemotherapy, overall response rate, safety, efficacy, Aichi Cancer Center, Novartis, Cancer Society

Posted Date: September 20th, 2019

DOl: https://doi.org/10.21203/rs.2.15054/v1

License: @ (i) This work is licensed under a Creative Commons Attribution 4.0 International License. Read Full License 


\section{Abstract}

One of the key oncogenic drivers in patients with non-small-cell lung cancer is rearrangements to the anaplastic lymphoma kinase, or ALK, gene. Inhibitors of this gene have led to promising responses in patients, but the gene rearrangements complicate treatment efforts by facilitating the emergence of drug resistance. To help overcome this, researchers are turning to the drug ceritinib. Results from the recent phase 2 ASCEND-9 study showed that ceritinib can lead to effective treatment responses when similar drugs like alectinib stop working. Ceritinib is a selective oral ALK inhibitor that's been approved for treating patients with metastatic ALK-positive non-small-cell lung cancer. The drug has demonstrated significant and meaningful improvements in progression-free survival in global phase 3 trials compared to chemotherapy. However, the efficacy and safety of ceritinib in patients who've grown resistant to the ALK inhibitor alectinib hasn't been clear. To answer this question, researchers used ceritinib to treat 20 patients with stage IIIb or IV ALK-positive non-small-cell lung cancer who had previously been managed with alectinib. The median duration of exposure to ceritinib was 3.7 months. The primary endpoint was overall response rate, defined as the proportion of patients with a best overall confirmed response of complete response or partial response. The median duration of follow-up was 11.6 months. The results showed an overall response rate to ceritinib of $25 \%$, including one complete response. In addition, one responder with partial response had an L1196M ALK mutation. The team also measured a disease control rate of $70 \%$, and among patients who showed measurable disease at baseline, over $70 \%$ experienced a decrease in tumor burden. The median time to response was 1.8 months, and the median duration of response was 6.3 months. Beyond these promising statistics, the treatment also appeared to be safe, with no new or unexpected safety concerns identified. Overall, these findings demonstrate that ceritinib is capable of meaningful antitumor activity in ALK-rearranged patients with advanced non-smellcell lung cancer who have failed prior alectinib. Based on the results of this prospective trial, ceritinib could be considered a viable treatment option for this group. 